\title{
Retrovesical malignant fibrous histiocytoma: a rare tumor
}

\author{
Shuchita Pathak, ${ }^{1}$ Tej Prakash Soni, ${ }^{1}$ Anil Kumar Gupta, ${ }^{2}$ Lalit Mohan Sharma ${ }^{3}$
}

'Radiation Oncology, Bhagwan Mahaveer Cancer Hospital and Research Centre, Jaipur, India ${ }^{2}$ Surgical Oncology, Bhagwan Mahaveer Cancer Hospital and Research Centre, Jaipur, India ${ }^{3}$ Medical Oncology, Bhagwan Mahaveer Cancer Hospital and Research Centre, Jaipur, India

\section{Correspondence to} Dr Tej Prakash Soni,

drtejprakashsoni@yahoo.co.in

Accepted 20 November 2017

\section{SUMMARY}

Malignant fibrous histiocytoma (MFH) originating from the retrovesical space is a very rare tumour. A 61-yearold man presented to our hospital with complaints of retention of urine and burning sensation during micturition since 6 months. CT scan abdomen showed a large retrovesical mass between the urinary bladder and rectum, measuring $11 \times 9 \times 12 \mathrm{~cm}$, displacing the urinary bladder. Serum PSA (Prostate Specific Antigen) value was within normal range. Biopsy from retrovesical mass and immunohistochemistry was suggestive of MFH. Wide excision of the retrovesical mass was done. Histopathology confirmed the diagnosis of MFH. He received adjuvant radiotherapy. He is on regular followup since the last 2 years after radiotherapy with no signs and symptoms of disease recurrence.

\section{BACKGROUND}

Malignant fibrous histiocytoma (MFH) is the most common type of soft-tissue sarcoma. It mostly occurs at the thigh, buttock, groin, upper limb and rarely at retroperitoneal and head and neck locations. Retrovesical space is the region between the urinary bladder and rectum. Retrovesical MFH is an extremely rare tumour.

\section{CASE PRESENTATION}

A 61-year-old man presented with complaints of burning sensation during micturition and retention of urine since the last 6 months.

\section{INVESTIGATIONS}

Urine routine and microscopic investigation were within normal limits. Urine culture for bacteria was sterile. CT scan abdomen showed a large retrovesical enhancing mass lesion between the urinary bladder and rectum, measuring $11 \times 9 \times 12 \mathrm{~cm}$, displacing the urinary bladder, involving prostate and seminal vesicles. Routine blood investigation, renal function test and liver function test were all within normal limits. Serum PSA value was also within normal limits. Cystoscopy showed normal bladder mucosa with no evidence of bladder invasion. Biopsy from the retrovesical mass showed undifferentiated malignant mesenchymal tumour. Immunohistochemistry staining was positive for vimentin (figure 1), SMA (Smooth Muscle Actin), BCL-2, CD68, CD99 and negative for CK, CD34 and TLE-1, which was suggestive of MFH. Whole-body PET/CT scan found FDG (18F-fluorodeoxyglucose)avid retrovesical mass as described in CT scan with no evidence of distant metastasis (figure 2).

\section{TREATMENT}

Wide excision of the retrovesical mass was planned by the team of oncosurgeons and urologists. A midline incision was made in the lower abdomen wall. A large, capsulated pelvic mass (size $10 \times 10 \mathrm{~cm}$ ) was seen in the midline between the urinary bladder and rectum, displacing and compressing the rectosigmoid colon posteriorly. No gross pelvic lymphadenopathy was seen. The mass was separated from the bladder and rectum. The tumour was excised en masse. Histopathology was reported $12 \times 12 \times 8 \mathrm{~cm}$ size well-encapsulated malignant mesenchymal tumour with all cut margins clear. The closest distance on normal tissue from cut margin was $1 \mathrm{~mm}$. Microscopic characteristics of the tumour were ovoid to spindloid cells arranged in fascicles with moderate pleomorphism, absent necrosis and atypical mitosis count $3 / 10$ high power fields (figure 3), suggestive of $\mathrm{MFH}$. $\mathrm{He}$ received adjuvant radiotherapy to the dose of $50 \mathrm{~Gy}$ in 25 fractions in 5 weeks with intensity-modulated radiation technique.

\section{OUTCOME AND FOLLOW-UP}

$\mathrm{He}$ is on regular follow-up since the last 2 years of radiotherapy with no signs and symptoms of disease recurrence. Recent MRI pelvis and follow-up CT scan chest show no evidence of disease recurrence.

\section{DISCUSSION}

MFH is composed of fibroblasts, myofibroblasts and histiocyte-like cells. The histopathological characteristic features of MFH are ovoid to spindloid cells arranged in fascicles with high cellularity, marked pleomorphism and frequent mitotic activity. MFH are poorly differentiated sarcomas that do not show any specific differentiation, except fibroblastic differentiation. The diagnosis of MFH is made by exclusion of other specific diagnoses like leiomyosarcoma or metastatic sarcomatoid carcinoma and melanoma.

In 2002, WHO modified the terminology. WHO advocated that the term MFH should be replaced by pleomorphic sarcoma as it provides an accurate description of the tumour without implying the origin of tumour cells. ${ }^{2}$ Immunohistochemical characteristics of MFH are positive staining for vimentin, SMA, alpha-1-antitrypsin, CD34 and CD68. ${ }^{1}$ Differential diagnosis of $\mathrm{MFH}$ includes 


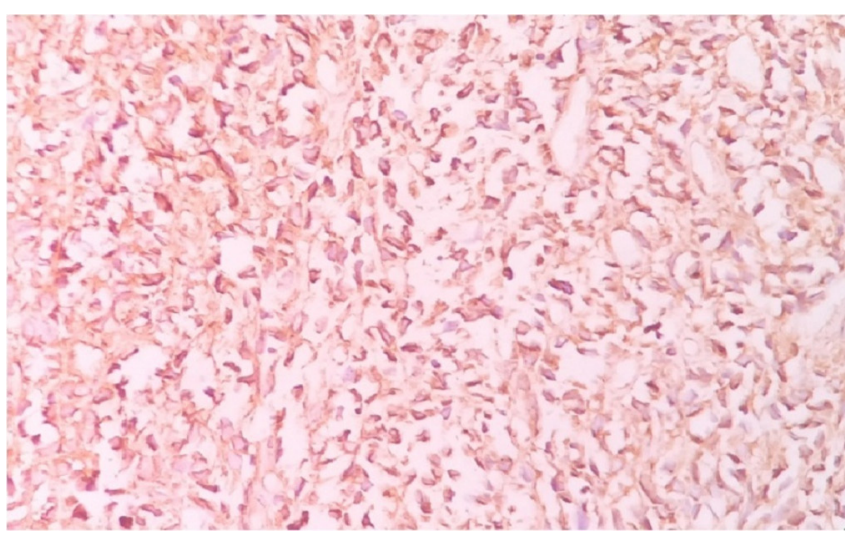

Figure 1 Immunohistochemistry analysis showing ( $\times 40$ view) undifferentiated malignant mesenchymal tumour cells with positive staining for vimentin.

leiomyosarcoma (positive desmin and SMA), liposarcoma (lipoblast present, SMA positive), pleomorphic rhabdomyosarcoma (positive desmin and muscle-specific actin) and synovial sarcoma (positive cytokeratin, EMA (Epithelial Membrane Antigen) synthesis and CD99).

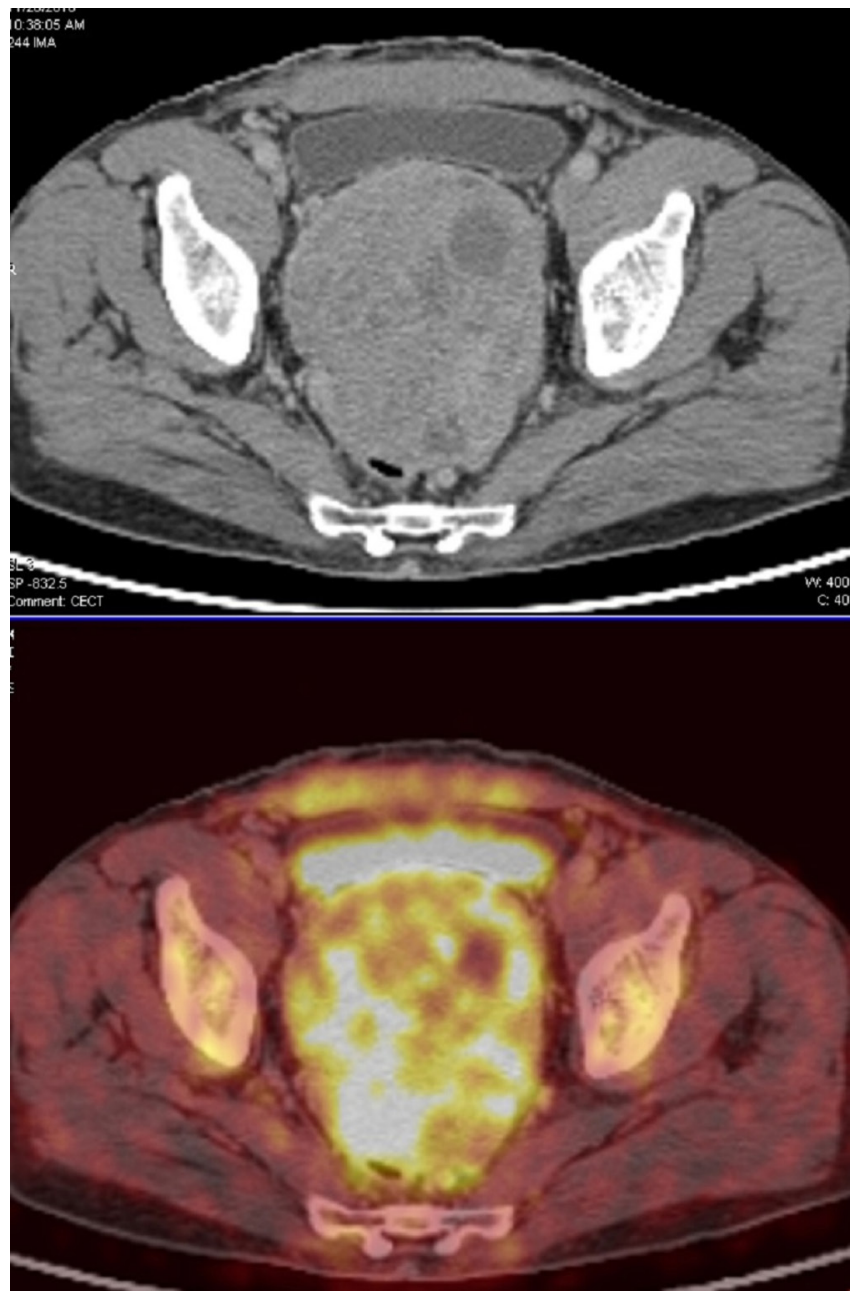

Figure 2 PET/CT scan abdomen showed a large retrovesical enhancing mass lesion between the urinary bladder and rectum, measuring $11 \times 9 \times 12 \mathrm{~cm}$, displacing the bladder, involving prostate and seminal vesicles.

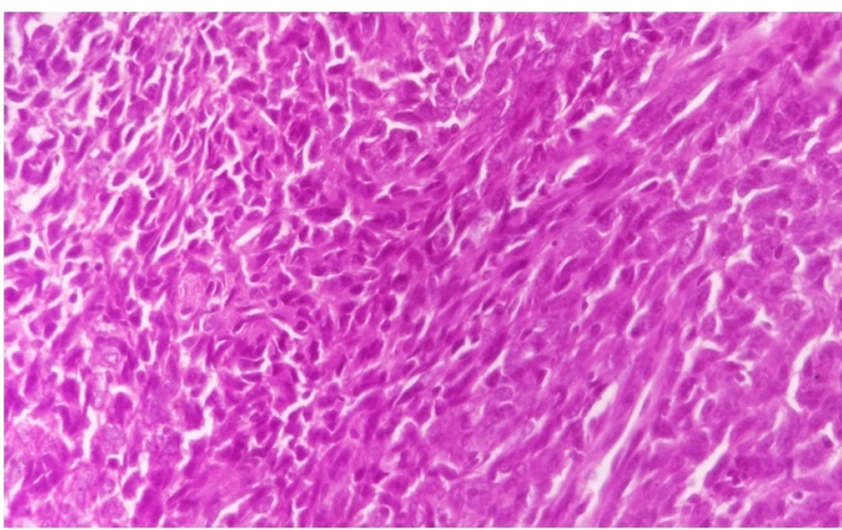

Figure 3 Microscopic characteristics (H\&E stained, $\times 40$ view) of mesenchymal tumour showing ovoid to spindloid cells arranged in fascicles with moderate pleomorphism, absent necrosis, atypical mitosis count $3 / 10$ high power fields.

MFH generally occurs in the sixth and seventh decades of life. Ten per cent of cases may present with distant metastasis by haematogenous spread. The lung is the most common site of distant metastasis. The most common site for MFH is the lower extremity especially in the thigh; other sites include the upper extremity, rarely retroperitoneum and head and neck region. Rare and uncommon sites of MFH are reported to occur in the heart, lungs, stomach, liver, kidneys, scrotum, bladder, orbit and vas deferens. $^{3-5}$

The retrovesical space is the region between the urinary bladder and rectum. Very few retrovesical space primary tumours are reported in the literature. ${ }^{67}$ Sarcoma originating from the retrovesical space is extremely rare. ${ }^{8}$

MRI is the imaging of choice as it provides information about lesion size, location, assessment of soft tissue and bones, and proximity to neurovascular structure or surrounding organs. ${ }^{9}$

Surgery, mainly wide excision with $1-2 \mathrm{~cm}$ safe normal tissue margin, is the mainstay of treatment. Indications of adjuvant radiotherapy include positive or close cut margins, higher grade and large size tumour. ${ }^{10}$ Usually, 45 Gy to 60 Gy dose in 25-30 fractions in 5 to 6 weeks of adjuvant or neoadjuvant radiotherapy is given. Chemotherapy has no clear role. In a large meta-analysis, adjuvant doxorubicin failed to improve the overall survival. $^{11}$

Despite adequate treatment with surgery and radiotherapy, $\mathrm{MFH}$ has poor prognosis with a high risk of local and systemic recurrence. The most important prognostic factors of MFH include the size of the tumour, grade of the tumour, depth of the tumour and cut margin status. ${ }^{12}$

\section{Learning points}

- Retrovesical malignant fibrous histiocytomas are rare tumours.

- Radical treatment of malignant fibrous histiocytoma is complete surgical excision.

- Large lesion size, high-grade tumour, positive or close cut margins are indications of adjuvant radiotherapy.

Contributors SP, TPS, AKG, LMS: substantial contributions to the conception or design of the work, or the acquisition, analysis or interpretation of data for the work; drafting the work or revising it critically for important intellectual content; final approval of the version to be published; agreement to be accountable for all aspects 
of the work in ensuring that questions related to the accuracy or integrity of any part of the work are appropriately investigated and resolved.

Competing interests None declared.

\section{Patient consent Obtained.}

Provenance and peer review Not commissioned; externally peer reviewed.

(c) BMJ Publishing Group Ltd (unless otherwise stated in the text of the article) 2017. All rights reserved. No commercial use is permitted unless otherwise expressly granted.

\section{REFERENCES}

1 Dei Tos AP. Classification of pleomorphic sarcomas: where are we now? Histopathology 2006;48:51-62.

2 World Health Organization Classification of tumors. In: Fletcher CDM, Mertens F, eds. Pathology and genetics of tumors of soft tissue and bone. Lyon, France: IARC Press, 2002.

3 Rzyman W, Jaskiewicz K, Murawski M, et al. Primary malignant fibrous histiocytoma of the lung. Thorac Cardiovasc Surg 2007;55:186-9.
4 Oesterling JE, Epstein JI, Brendler CB. Myxoid malignant fibrous histiocytoma of the bladder. Cancer 1990;66:1836-42.

5 Azizi R, Mahjoubi B, Shayanfar N, et al. Malignant fibrous histiocytoma of rectum: report of a case. Int J Surg Case Rep 2011;2:111-3.

6 Tosaka A, Yamazaki A, Hirokawa M, et al. A bulky mass non-Hodgkin's lymphoma with dysuria in the rectovesical space. Hinyokika Kiyo 1990;36:701-5.

7 Wilson RG. Dermoid cyst of the rectovesical space: report of a case. Dis Colon Rectum 1973;16:530-1.

8 Kil MC, Cho BS, Han GS, et al. Synovial sarcoma in the rectovesical space: a case report. J Korean Soc Radiol 2011;65:167-70.

9 Faizi NA, Thulkar S, Sharma R, et al. Magnetic resonance imaging and positron emission tomography-computed tomography evaluation of soft tissue sarcoma with surgical and histopathological correlation. Indian J Nucl Med 2012;27:213-20.

10 Cheng EY, Dusenbery KE, Winters MR, et al. Soft tissue sarcomas: preoperative versus postoperative radiotherapy. J Surg Oncol 1996;61:90-9.

11 Sarcoma Meta-analysis Collaboration. Adjuvant chemotherapy for localised resectable soft-tissue sarcoma of adults: meta-analysis of individual data. Sarcoma Meta-analysis Collaboration. Lancet 1997;350:1647-54.

12 Coindre JM, Terrier P, Bui NB, et al. Prognostic factors in adult patients with locally controlled soft tissue sarcoma. A study of 546 patients from the French Federation of Cancer Centers Sarcoma Group. J Clin Oncol 1996;14:869-77.

Copyright 2017 BMJ Publishing Group. All rights reserved. For permission to reuse any of this content visit http://group.bmj.com/group/rights-licensing/permissions.

BMJ Case Report Fellows may re-use this article for personal use and teaching without any further permission.

Become a Fellow of BMJ Case Reports today and you can:

- Submit as many cases as you like

- Enjoy fast sympathetic peer review and rapid publication of accepted articles

- Access all the published articles

Re-use any of the published material for personal use and teaching without further permission

For information on Institutional Fellowships contact consortiasales@bmjgroup.com

Visit casereports.bmj.com for more articles like this and to become a Fellow 